\title{
Apoptosis in TMJ Disc Diseases
}

\author{
Giuseppe Musumeci*, Carla Loreto \\ Department of Bio-Medical Sciences, Human Anatomy and Histology Division, University of Catania, Catania, Italy \\ Email: "g.musumeci@unict.it
}

Received August 10, 2013; revised September 10, 2013; accepted September 18, 2013

Copyright (C) 2013 Giuseppe Musumeci, Carla Loreto. This is an open access article distributed under the Creative Commons Attribution License, which permits unrestricted use, distribution, and reproduction in any medium, provided the original work is properly cited.

The apoptosis is the programmed cell death, a distinct process compared to cellular necrosis, which plays an important role in both human embryonic development and adult tissue homeostasis. Apoptosis represents a physiological form of cell death. The role of apoptosis is to remove harmful, damaged or unwanted cells without inducing inflammatory response by the release of cell contents [1]. Apoptosis is activated through two principal signaling pathways: intrinsic and extrinsic, both of which are potential anticancer therapeutic targets. In contrast to necrosis, which is a form of cell death resulting from an acute cellular stress or trauma, apoptosis is a death orderly and regular, does not induce inflammation, requires energy (ATP) and generally lead to an advantage during the body life. Besides its importance as a biological phenomenon, it has acquired a huge medical value, since imperfect process of apoptosis covers many diseases. Excessive activity can cause trouble by apoptotic cell loss (see, for example neurodegenerative diseases such as Parkinson's disease), while a weak apoptosis may involve uncontrolled cell growth in malignancy mechanism [2]. Apoptosis is the most common mechanism by which the body eliminates damaged or unneeded cells, without local inflammation from leakage of cell contents. Cells that are undergoing apoptosis exhibit a characteristic pattern of morphologic changes, including cell shrinkage, condensation, fragmentation of the nucleus and bubbling of the plasma membrane, known as "blebbing," and chromatin condensation and nucleosomal fragmentation $[1,3]$. Apoptosis functions through two main, alternative pathways: death receptor-mediated (or extrinsic) and mitochondria-dependent (or intrinsic). The former pathway is initiated by ligation of specific death receptors by their ligands. The main death receptors-Fas and tumour necrosis factor (TNF)-related apoptosis inducing ligand (TRAIL) receptors R1 and R2-induce cell death following ligation with Fas ligand (FasL) or TRAIL, respectively [4-7]. Ligation of TRAIL R1 by $\mathrm{TNF} \alpha$ also in-

\footnotetext{
*Corresponding author.
}

duces apoptosis after inhibition of nuclear factor kappa-B (NF-kB). Fas ligation by FasL is followed by recruitment of FADD (Fas-associated via death domain) and subsequently of caspase 8 . This process gives rise to caspase 8 activation, which can be inhibited by the anti-apoptotic molecule FLICE inhibitory protein (Flip). Caspase 8 induces apoptosis by directly activating caspase 3 or by cleaving bid (BH3 interacting domain death agonist), resulting in mitochondrial dysfunction and subsequent release of cytochrome c and activation of caspases 9 and 3 . Caspase 3 promotes the typical apoptosis features, including DNA fragmentation and cell death in several tissues $[8,9]$.

It is unclear whether repetitive loading and apoptosis are quantitatively related in any type of cartilage. Several studies have demonstrated the crucial function of apoptotic mechanisms in intervertebral disc degeneration, and the involvement of apoptosis in various conditions associated with intervertebral disc degeneration has been thoroughly explored [10]. However, apoptosis has been documented to have a central role not only in intervertebral disc degeneration [10].

Although a number of features of temporomandibular joint (TMJ) disc degeneration have been thoroughly studied, data on the involvement of apoptotic mechanisms and their mediators are few and quite recent; indeed most of the research conducted on disc apoptosis has focused on the intervertebral disc. TMJ disc degeneration is believed to be a consequence of mechanical and biological events affecting the equilibrium between matrix synthesis and degradation. According to this hypothesis loss of cellularity, collagen fibre fragmentation and TMJ disc tears and clefts would all depend on excessive apoptosis, a situation where collagen fibre degradation is not offset by synthesis of new fibres because of apoptosis-induced cell loss. The findings correlating TMJ disc internal derangement and apoptosis largely come from animal models [11]. However, our group has extensively analyzed programmed cell death in human TMJ discs with and without internal derangement $[12,13]$. We have advanced 
the hypothesis that the degenerative changes seen in discs with internal derangement must include an active cell response with a change in cell phenotype from fibroblast-like to fibrochondrocyte, and eventually to chondrocyte-like, possibly as a response to abnormal loading. We did find activation of apoptosis via the extrinsic and the intrinsic pathway, and noted that the degree of apoptosis activation correlated with the degree of disc degeneration. Authors demonstrated that Bcl-2 and Bax oncoproteins are physiologically expressed in the rabbit craniomandibular joint, so we investigated the activation of the intrinsic pathway and demonstrated an involvement of these molecules in human TMJ disc with internal deragement [14]. In fact the mitochondrial pathway is partly influenced by $\mathrm{Bcl}$ family members bound to the mitochondrial membrane, including Bax and $\mathrm{Bcl}-2$, which are respectively proor anti-apoptotic regulatory proteins. The anti-apoptotic proteins Bcl-2 and Bcl-XL inhibit cytochrome c release, whereas $\mathrm{Bcl}-2$-associated $\mathrm{X}$ protein (Bax), Bcl-2 homologous antagonist/killer (Bak), and Bid, all pro-apoptotic proteins, promote its release from mitochondria. Cytochrome $\mathrm{c}$ and deoxyadenosine triphosphate (dATP) bind to apoptotic protease activating factor (Apaf-1) to form a multimeric complex that recruits and activates procaspase 9 , an apoptosis-mediating executioner protease that in turn activates caspase 3 , resulting in cell apoptosis.

Other studies carried out by us demonstrated the presence of vessel apoptosis in TMJ discs with internal derangement [15]. The findings generated the hypothesis that apoptosis activation could be a self-limiting process that aims to reverse the angiogenesis typically seen in these discs [15]. The strong immunoexpression of TRA$\mathrm{IL}$, its receptor DR5 and caspase 3 documented in the intima and media layers of newly formed vessels seems indeed to reflect the defensive activation of the apoptosis process [15].

A therapeutic approach aimed at neutralizing apoptosis-inducing molecules would at least help delay the progression of disc degeneration. Identification of target molecules for gene construction or biological or chemical reagent delivery to target sites could help prevent TMJ disc degeneration. Further longer-term in vitro, in vivo and clinical studies are needed to understand the exact role of apoptosis in the TMJ disc degeneration mechanism.

\section{REFERENCES}

[1] G. Musumeci, C. Loreto, M. L. Carnazza and G. Martinez, "Characterization of Apoptosis in Articular Cartilage Derived from the Knee Joints of Patients with Osteoarthritis," Knee Surgery Sports Traumatology Arthroscopy, Vol. 19, No. 2, 2011, pp. 307-313. http://dx.doi.org/10.1007/s00167-010-1215-0
[2] S. De Maria, G. Pannone, P. Bufo, A. Santoro, R. Serpico, S. Metafora, et al., "Survivin Gene-Expression and Splicing Isoforms in Oral Squamous Cell Carcinoma,” Journal of Cancer Research and Clinical Oncology, Vol. 135, No. 1, 2009, pp. 107-116. http://dx.doi.org/10.1007/s00432-008-0433-z

[3] R. Rezzani, A. Stacchiotti and L. F. Rodella, "Morphological and Biochemical Studies on Aging and Autophagy,” Ageing Research Reviews, Vol. 11, No. 1, 2012, pp. 10-31. http://dx.doi.org/10.1016/j.arr.2011.09.001

[4] C. Loreto, G. Barbagli, R. Djinovic, G. Vespasiani, M. L. Carnazza, R. Miano, et al., "Tumor Necrosis Factor-Related Apoptosis-Inducing Ligand (TRAIL) and Its Death Receptor (DR5) in Peyroniet's Disease. A Biomolecular Study of Apoptosis Activation," Journal of Sexual Medicine, Vol. 2011, No. 1, 2011, pp. 109-115. http://dx.doi.org/10.1111/j.1743-6109.2010.02003.x

[5] C. Loreto, L. E. Almeida, P. Trevilatto and R. Leonardi, "Apoptosis in Displaced Temporomandibular Joint Disc with and without Reduction: An Immunohistochemical Study," Journal of Oral Pathology and Medicine, Vol. 40, No. 1, 2011, pp. 103-110. http://dx.doi.org/10.1111/j.1600-0714.2010.00920.x

[6] C. Loreto, L. E. Almeida, M. R. Migliore, M. Caltabiano and R. Leonardi, "TRAIL, DR5 and Caspase 3-Dependent Apoptosis in Vessels of Diseased Human Temporomandibular Joint Disc. An Immunohistochemical Study," European Journal of Histochemistry, Vol. 54, No. 3, 2010, pp. 175-179. http://dx.doi.org/10.4081/ejh.2010.e40

[7] V. Cardile, G. Musumeci, E. Sicurezza, S. Caggia, M. C. Rusu, R. Leonardi and C. Loreto, "TRAIL and Its Receptors DR5 and DcR2 Expression, in Orthodontic Tooth Movement," Histology and Histopathology, 2013 (in press).

[8] C. Loreto, G. Musumeci and R. Leonardi, "Chondrocyte-Like Apoptosis in Temporomandibular Joint Disc Internal Derangement as a Repair-Limiting Mechanism. An in Vivo Study," Histology and Histopathology, Vol. 24, No. 3, 2009, pp. 293-298.

[9] C. Loreto, C. Galanti, R. Leonardi, G. Musumeci, G. Pannone, G. Palazzo, et al., "Possible Role of Apoptosis in the Pathogenesis and Clinical Evolution of Radicular Cyst. An Immunohistochemical Study," International Endodontic Journal, 2013 (in press). http://dx.doi.org/10.1111/iej.12040

[10] C. Loreto, G. Musumeci, A. Castorina, C. Loreto and G. Martinez, "Degenerative Disc Disease of Herniated Intervertebral Discs Is Associated with Extracellular Matrix Remodeling, Vimentin-Positive Cells and Cell Death," Annual of Anatomy, Vol. 193, No. 2, 2011, pp. 156-162. http://dx.doi.org/10.1016/j.aanat.2010.12.001

[11] Q. Huang, B. Singh and M. Sharawy, "Immunohistochemical Analysis of Bcl-2 and Bax Oncoproteins in Rabbit Craniomandibular Joint," Archives of Oral Biology, Vol. 49, No. 2, 2004, pp. 143-148. http://dx.doi.org/10.1016/j.archoralbio.2003.07.003

[12] R. Leonardi, L. E. Almeida, P. C. Trevilatto and C. Loreto, "Occurrence and Regional Distribution of TRAIL and DR5 on Temporomandibular Joint Discs: Comparison of Disc Derangement with and without Reduction," 
Oral Surgery, Oral Medicine, Oral Pathology, Oral Radiology and Endodontology, Vol. 109, No. 2, 2010, pp. 244-251. http://dx.doi.org/10.1016/j.tripleo.2009.09.028

[13] R. Leonardi, L. E. Almeida, M. Rusu, E. Sicurezza, G. Palazzo and C. Loreto, “Tumor Necrosis Factor-Related Apoptosis-Inducing Ligand Expression Correlates to Temporomandibular Joint Disk Degeneration,” Journal of Craniofacial Surgery, Vol. 22, No. 2, 2011, pp. 504-508. http://dx.doi.org/10.1097/SCS.0b013e3182087394

[14] R. Caltabiano, R. Leonardi, G. Musumeci, G. Bartoloni, M. C. Rusu, L. E. Almeida and C. Loreto, "Apoptosis in
Temporomandibular Joint Disc with Internal Derangement Involves Mitochondrial-Dependent Pathways. An in Vivo Study," Acta Odontologica Scandinavica, Vol. 71, No. 3-4, 2013, pp. 577-583.

http://dx.doi.org/10.3109/00016357.2012.700060

[15] C. Loreto, L. E. Almeida, M. R. Migliore, M. Caltabiano and R. Leonardi, "TRAIL, DR5 and Caspase 3-Dependent Apoptosis in Vessels of Diseased Human Temporomandibular Joint Disc. An Immunohistochemical Study,” European Journal of Histochemistry, Vol. 54, No. 3, 2010, p. E40. http://dx.doi.org/10.4081/ejh.2010.e40 